\title{
ХРОМШПИНЕЛИДЫ - КАК ИНДИКАТОР ТИПИЗАЦИИ УЛЬТРАМАФИТОВ СПОРНОГО ГЕНЕЗИСА
}

\author{
Голубева И.И., Филиппов В.Н., Бурцев И.Н. \\ Институт геологии Коми НЦ УрО РАН, iigolubeva@geo.komisc.ru
}

На Среднем Тимане в пределах юго-восточной части Четласского поднятия развиты своеобразные ультрамафиты, относимые к четласскому комплексу щелочных пикритов [3]. Становление этого комплекса связано с байкальским тектоно-магматическим циклом и имеет возраст 590-598 млн. лет [4]. Породы представлены субвертикальными телами с мощностью от десятков сантиметров до десятков метров в раздувах, имеют протяженность до 3 км. По геофизическим данным, неглубокими скважинами и наземными горными работами, были выявлены около тысяч даек, расположенных на площади около 1000 км ${ }^{2}$. Дайки имеют многофазное строение, обусловленное присутствием пород предыдущих фаз внедрения. В породах отмечаются ксенолиты мантийных и вмещающих пород, погруженные в матрикс с варьирующим количеством минералов разного генезиса (магматогенного и метасоматического). Породы подвержены процессами карбонатизации и флогопитизации вплоть до слюдитов и карбонатитов. Изменчивый минеральный состав пород, но индивидуальный для определенного дайкового тела, приводит к разным диагностическим выводам исследователей. В производственных отчетах и научных статьях породы трактуются как кимберлиты, слюдистые лампрофиры, меланократовые минетты или лампрофиры, лампрофиры керсантитспессартитового ряда, щелочные пикриты [2; 5]. В наше распоряжение был представлен керн скважины № 55 глубиной 173 м, прошедшей вдоль двух параллельных даек мощностью около 5 м. Породы плотного сложения имеют черный цвет. Отмечается большое количество ксенолитов мантийных пород и минералов, а так же коровых (вмещающих) пород. Ксенолиты мантийных пород с размерами до 10 см представлены вебстеритами и горнблендитами. Ксеногенные обломки минералов - оливина (2-10\%), моноклинного пироксена (3-5\%), хромшпинелида в породе отличаются большими размерами и обуславливают порфирокластовую структуру. Матрикс представляет собой мелкозернистый агрегат разнородный по количественному составу магматогенных и вторичных минералов: моноклинный пироксен, роговая обманка, флогопит, кальцит, хлорит, эпидот. Текстура основной массы массивная или флюидальная. Породы изучаемых даек имеют в среднем химический состав (в масс. \%): $\mathrm{SiO}_{2}=41.2 ; \mathrm{TiO}_{2}=1.26 ; \mathrm{Al}_{2} \mathrm{O}_{3}=9.7 ; \mathrm{Fe}_{2} \mathrm{O}_{3}=3.2 ; \mathrm{FeO}=5.3 ; \mathrm{MgO}=16.1$; $\mathrm{CaO}=11.99 ; \mathrm{Na}_{2} \mathrm{O}=0.79 ; \mathrm{K}_{2} \mathrm{O}=3.3 ; \mathrm{P}_{2} \mathrm{O}_{5}=0.36$, отличимый от щелочных пикритов пониженным содержанием магния, высоким количеством щелочей и кальция.

Хромшпинелид является одним из косвенных минеральных индикаторов генезиса магматических пород. В данном случае породы интересны не только как петрологический объект, но и как перспективные на алмазоносность [1; 6; 8], так как вблизи даек в аллювиальных отложениях и в самих породах известны находки алмазов уральского типа. В изучаемых ультрамафитах хромшпинелид, как уже отмечалось, встречается только как ксеногенный в виде изометричных обломков с размерностью до 0.6 мм. Минерал представлен двумя разновидностями - среднехромистым хромшпинелидом и железистой шпинелью. В микроскопе при одном поляризаторе хромшпинелид имеет красный цвет, а железистая разновидность шпинели - зеленый. Хромшпинелид с меньшими размерами (0.1-0.2 мм) встречается в мантийных ксенолитовых обломках оливина и вебстерита. Хромшпинелид представлен среднехромистой разновидностью со следующим составом (масс. \%): $\mathrm{TiO}_{2}=0-1.51 ; \mathrm{Al}_{2} \mathrm{O}_{3}=12.2-41.0 ; \mathrm{Cr}=17.42-51.45 ; \mathrm{FeO}+\mathrm{F}_{2} \mathrm{O}_{3}=12.55-20.29 ; \mathrm{MgO}=12.05-20.43$ (табл. 1). На тройной диаграмме $\mathrm{Al}^{3+}-\mathrm{Cr}^{3+}-\mathrm{Fe}^{3+}$ наблюдаются изоморфные замещения между хромом и алюминием, что предполагает перидотит-пироксенитовый магматический эволюционный тренд (рис. 1 а). В нашем случае хромшпинелиды образуют неполный $\mathrm{Al}^{3+}-\mathrm{Cr}^{3+}$ тренд, соответствующий пироксенитовому генезису. На этом же графике размещены результаты химических анализов хромшпинелидов из других даек, удаленных друг от друга на значительные расстояния. Фигуративные точки хромшпинелидов расположились в одном поле, что подтверждает их единый генезис и однородность мантии на данном участке Среднего Тимана. Перидотит-пироксеновый 

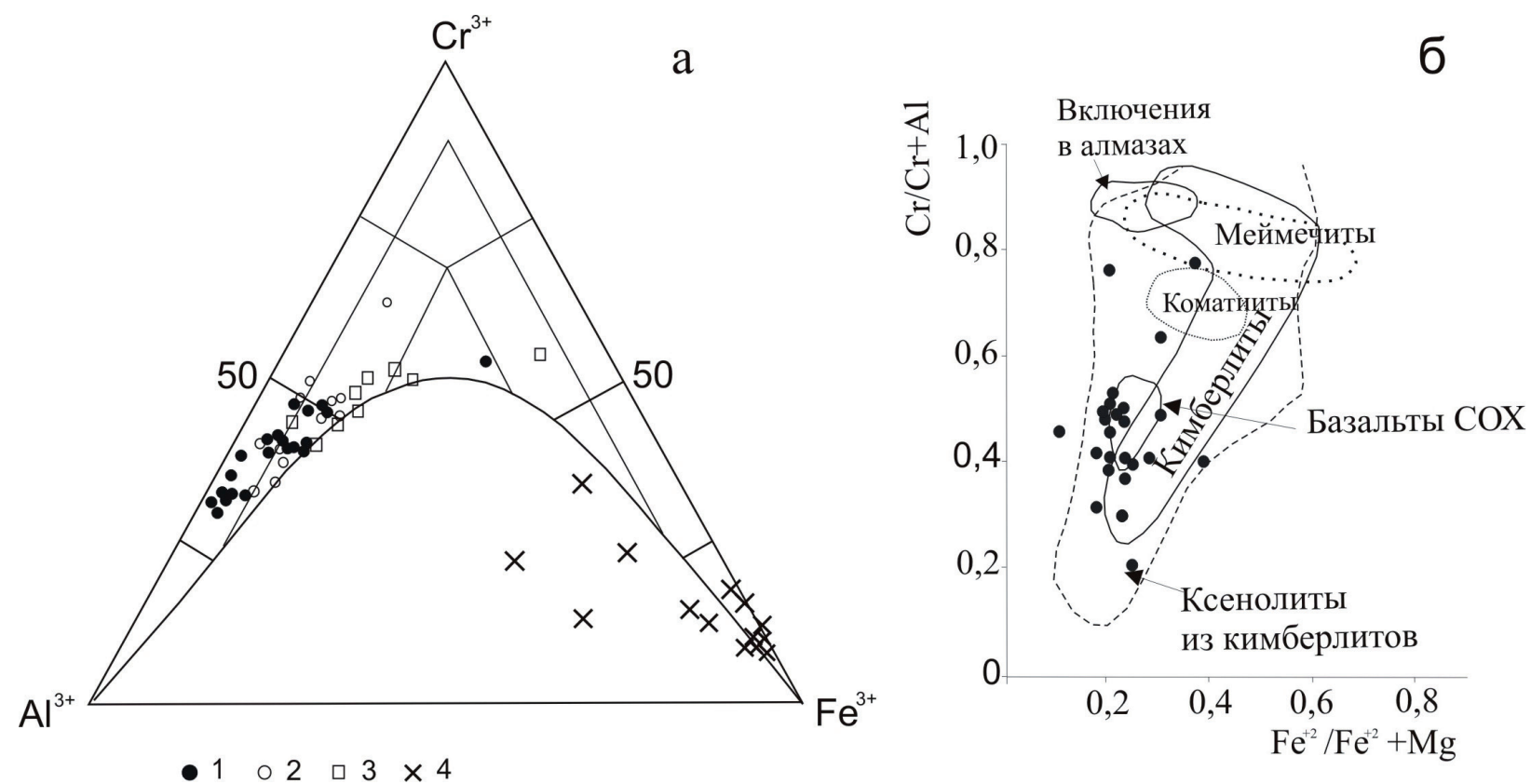

Рис.1 Особенности составов хромшпинелида на тройной диаграмме $\mathrm{Al} 3+-\mathrm{Cr} 3+-\mathrm{Fe} 3+$ (a); на двойной диаграмме $\mathrm{Cr} / \mathrm{Cr}+\mathrm{Al} \neg \mathrm{Fe}+2 / \mathrm{Fe}+2+\mathrm{Mg}$ (б).

Условные обозначения: 1 - хромшпинелид скважины № 55; 2 - хромшпинелид других скважин по [5]; 3 - ранняя реакционная кайма хромшпинелида; 4 - поздняя реакционная кайма хромшпинелида.
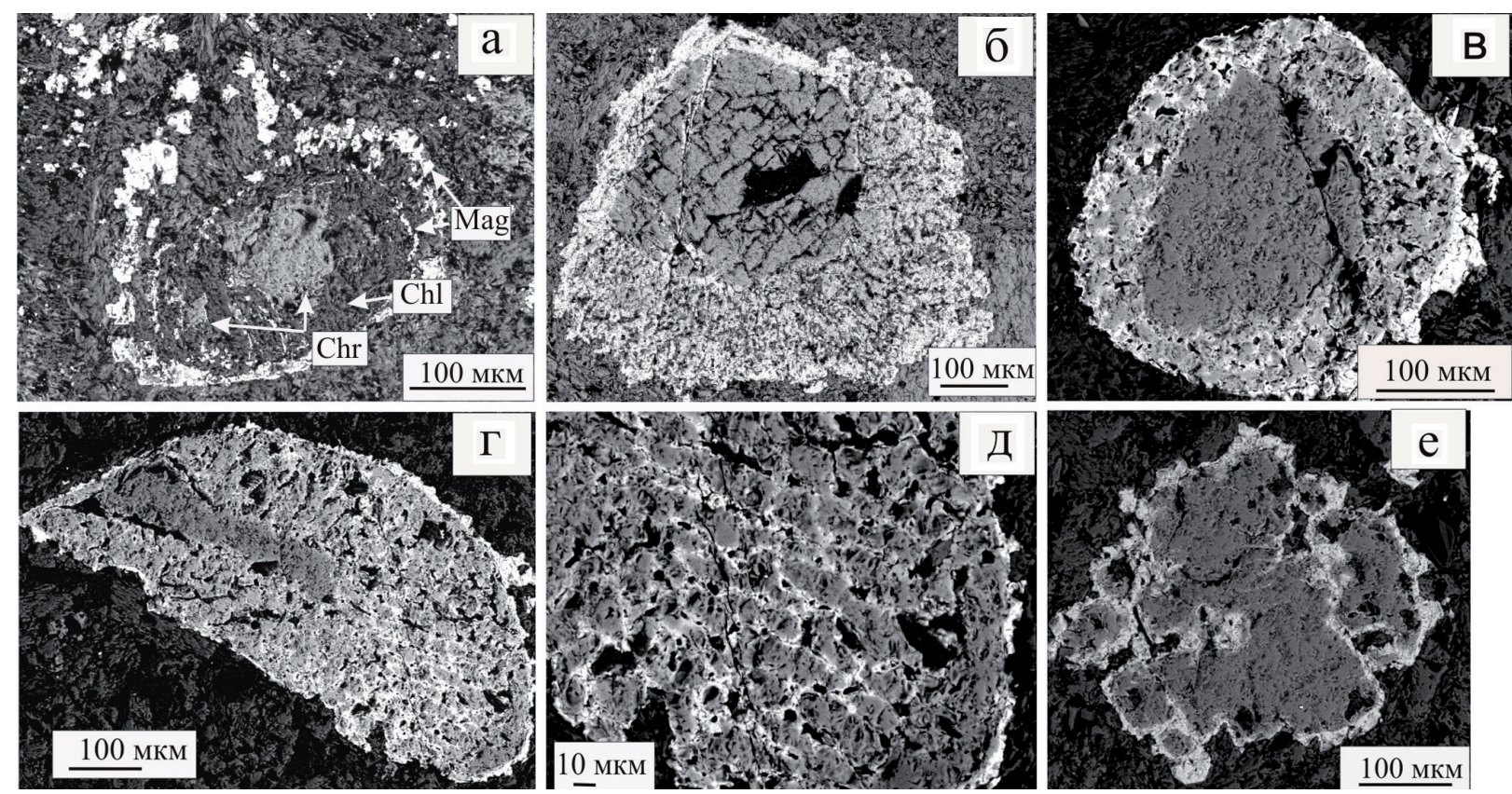

Рис. 2. Электронно-микроскопические изображения реакционных каемок хромшпинелидов (в режиме упруго-отраженных электронов).

a - железистая шпинель, замещаемая последовательно хлоритом и магнетитом; б - ранняя реакционная кайма; в - ранняя и поздняя магнетитовая реакционная кайма с выростами крючкообразной формой; г - ранняя реакционная кайма пористой структуры; д - увеличенный фрагмент пористой структуры реакционной каймы хромшпинелида Хорошо видно развитие магнетитовой каймы в виде выростов грибообразной формы; е - поздняя магнетитовая кайма около хромшпинелида.

тренд хромшпинелида прослеживается и на графике $\mathrm{Cr} / \mathrm{Cr}+\mathrm{Al} \mathrm{Fe}^{+2} / \mathrm{Fe}^{+2}+\mathrm{Mg}$ (рис. 1 б) [9]. В минерале отмечается повышенное количество титана (в среднем 0.66 масс. \%) и существенный диапазон значений (в масс. \%) от 0 до 1.51. Повышенный титан и неравномерное его распределе- 
ние объясняется мантийной метасоматической переработкой пироксенитов. Железистая зеленая шпинель в описываемых породах является редкостью и отличается относительно большими размерами (до 1 мм). Характеризуется так же повышенным содержанием $\mathrm{TiO}_{2}(0.47-0.54$ масс. \%), высоким количеством $\mathrm{Al}_{2} \mathrm{O}_{3}$ (49.91-61.15 масс.\%) и весьма незначительной примесью $\mathrm{Cr}_{2} \mathrm{O}_{3}$ (0-0.25 масс.\%). Отмечаются практически равные количества магния и суммы железа (масс.\%): $\mathrm{MgO}=16.67-19.59$, $\mathrm{FeO}+\mathrm{F}_{2} \mathrm{O}_{3}=18.74-22.69$. Шпинель в процессе становления породы последовательно замещается хлоритом, а затем магнетитом (рис. 2 а). Стадийность замещения характерна и для хромшпинелида, отражающая процессы эволюции расплава в коровых условиях и постмагматическое преобразование породы. На тройной диаграмме $\mathrm{Al}^{3+}-\mathrm{Cr}^{3+}-\mathrm{Fe}^{3+}$ хорошо прослеживается реакционный тренд изоморфизма $\mathrm{Cr}^{3+}+\mathrm{Al}^{3+}-\mathrm{Fe}^{3+}$, подобный пикритовому, связанный с реагированием минерала с флюидонасыщенным расплавом (рис. 1 a). Визуально этот процесс хорошо виден на микрозондовых снимках в виде каймы пористой структурой с заливообразными краями, повторяющей первичные контуры замещаемого минерала (рис. 2 б-д). В поляризационном микроскопе в проходящем свете кайма диагностируется черным непроницаемым цветом вокруг просвечивающим красным хромшпинелида. Реакционная кайма имеет разную ширину вплоть до полного замещения первичного минерала, но в случае отсутствия диагностируется только магнетитовая (рис. 2 е). Состав реакционной каймы отличается от первичного мантийного хромшпинелида повышенным содержанием общего количества железа и пониженным магнием со средним значением 11.06 мас. \% (табл.1). В некоторых случаях отмечаются в небольших количествах примеси $\mathrm{MnO}$ (в среднем

Таблица 1. Химический состав хромшпинелида и реакционных каемок ( в масс. \%).

\begin{tabular}{|c|c|c|c|c|c|c|c|c|c|}
\hline & \multirow{2}{*}{\multicolumn{3}{|c|}{$\begin{array}{l}\text { Центральная часть зерна } \\
\qquad(\mathrm{n}-26)\end{array}$}} & \multicolumn{6}{|c|}{ Реакционная кайма } \\
\hline & & & & \multicolumn{3}{|c|}{ ранняя $(\mathrm{n}-15)$} & \multicolumn{3}{|c|}{ поздняя (n - 20) } \\
\hline & $\mathrm{X}$ min & $\mathrm{X} \max$ & $\mathrm{X}$ middl & $\mathrm{X}$ min & $\mathrm{X} \max$ & $\mathrm{X}$ middl & $\mathrm{X}$ min & $\mathrm{X} \max$ & $\mathrm{X}$ middl \\
\hline $\mathrm{TiO}_{2}$ & 0 & 1.51 & 0.66 & 0 & 0.98 & 0.54 & 0 & 6.26 & 1.6 \\
\hline $\mathrm{Al}_{2} \mathrm{O}_{3}$ & 12.2 & 41.0 & 29.6 & 7.07 & 29.47 & 22.2 & 0 & 8.23 & 1.4 \\
\hline $\mathrm{Cr}_{2} \mathrm{O}_{3}$ & 17.42 & 51.45 & 34.1 & 25.41 & 39.65 & 34.4 & 2.23 & 29.28 & 8.43 \\
\hline $\mathrm{FeO}^{*}$ & 12.55 & 20.29 & 16.7 & 16.57 & 50.86 & 28.0 & 42.10 & 98.14 & 79.1 \\
\hline $\mathrm{MgO}$ & 12.05 & 20.43 & 17.53 & 1.29 & 18.1 & 11.06 & 0 & 2.99 & 0.73 \\
\hline $\mathrm{MnO}$ & 0 & 0 & 0 & 0 & 2.99 & 0.39 & 0 & 2.74 & 0.82 \\
\hline $\mathrm{ZnO}$ & 0 & 0 & $\mathbf{0}$ & 0 & 2.29 & 0.15 & 0 & 1.75 & 0.48 \\
\hline
\end{tabular}

0.39 масс. \%) и $\mathrm{ZnO}_{2}$ (в среднем $0.15 \%$ мас. \%). Оцинкование хромшпинелидов происходит, обычно, в гидротермально-метасоматических и гидрогенных условиях [7]. В нашем случае цинксодержащие каемки образовались за счет реакционного реагирования обломков низкохромистого хромшпинелида пироксенитового генезиса с флюидонасыщенным щелочным мантийным расплавом. Высокая насыщенность летучими компонентами расплава, как уже упоминалось выше, приводит на конечных стадиях формирования пород к образованию карбонатитов и флогопитовых слюдитов. Метасоматические процессы происходили одновременно с дезинтеграцией сформировавшихся ранее мономинеральных карбонатных или слюдистых участков, так как в породе нередко встречаются фрагменты пород кальцитового или флогопитового состава, растащенных, впоследствии на отдельные фрагменты флюидизированным высокотекучим расплавом. На последних стадиях становления породы пропитываемой остывающими растворами около хромшпинелида формируется поздняя кайма магнетитового состава. Об этом свидетельствуют выросты, образованные на краю магнетитовой каймы, крючкообразной, грибообразной или другой неправильной формами, развивающиеся в межзерновом пространстве контактирующих минералов (рис. 2 в; д; е). Прерывистость образования зональных реакционных каемок иллюстрирует тройная диаграмма $\mathrm{Al}^{3+}-\mathrm{Cr}^{3+}-\mathrm{Fe}^{3+}$, на которой хорошо виден обособленный эволюционный тренд кристаллизации магнетита. Поздняя маг- 
нетитовая оторочка имеет переменный химический состав (рис. 2 а). Помимо главных компонентов оксидов железа (в среднем 79.1 масс.), отмечается постоянная примесь $\mathrm{Cr}_{2} \mathrm{O}_{3}$ в количестве от 2.23 до 29.28 масс. \% (табл. 1). Количество $\mathrm{TiO}_{2}, \mathrm{MgO}_{\text {и }} \mathrm{Al}_{2} \mathrm{O}_{3}$ резко уменьшается до полного исчезновения. Элементы $\mathrm{Mn}$ и $\mathrm{Zn}$ в среднем соответственно (в мас. \%) 0.82 и 0.48 отличаются повышенным содержанием по сравнению с ранней каймой, но в некоторых случаях данные элементы могут отсутствовать. Оцинкование хромшпинелида на этом этапе происходило за счет гидротрмальнометасоматических процессов, прошедших в сформировавшейся породе.

Таким образом, химический состав хромшпинелидов описываемых ультрамафитов отвечает мантийному пироксенитовому генезису и не подтверждает его пикритовую природу. Преобразование минерала отражает эволюционный процесс становления мантийной породы в земной коре.

\section{Литература}

1. Гаранин В.К. Полигенность природного алмазообразования // Фундаментальные проблемы геологии месторождений полезных ископаемых и металлогении. Москва. 2010. Т. 2. С. 157-175.

2. Голубева И.И., Бурцев И.Н. Проблема типизации щелочных ультрамафитов дайкового комплекса Среднего Урала // Петрография магматических и метаморфических горных пород. Петрозаводск. 2015. C. 551-554.

3. Государственная геологическая карта Российской федерации. Масштаб: 1000000 ( третье поколоение). Лист Q - 39. Объяснительная записка. СПб: Ид-во СПб Картография. ВСЕГЕИ. 2015.

4. Костюхин М.И., Степаненко В.И. Байкальский магматизм Канино-Тиманского региона: Л.: Наука. 1987. $232 \mathrm{c}$.

5. Макеев А.Б., Лебедев В.А., Брянчанинова Н.И. Магматиты Среднего Тимана. Екатеринбург. 2008. 312 с.

6. Саблуков С.М., Каминский Ф.В., Саблукова Л.И. Древние алмазоносные изверженные породы некемберлитового типа // Проблемы источников шлубинного магматиза и плюмы. Иркутск, 2005. С. 116-133.

7. Силаев В.И., Голубева И.И., Хазов А.Ф. и др. Цинкосодержащие и цинкистые хромшпинелиды: химизм и типоморфные значение // Сыктывкарский минералогический сборник. Сыктывкар. 2010. Вып. 126. № 36. С. 110-180.

8. Щека С.А., Волохин Ю.Г., Карабцов А.А. Первая находка эксплозивных щелочных пикритов в Наданьхада-Алине (КНР). Геохимия. ДАН. 2009. Т. 429. № 3. С. 373-387.

9. Barnes S.J., Roeder P.L. The Range of Spinel Compositions in Terrestrial Mafic and Ultramafic Rocks. Journal of petrology. 2001. V. 42. № 12. P. 2279-2302. 